\title{
Interaction of the San Andreas Fault Creeping Segment with Adjacent Great Rupture Zones and Earthquake Recurrence at Parkfield
}

\author{
YEHUDA BEN-ZION, JAMES R. RICE, AND RENATA DMOWSKA \\ Department of Earth and Planetary Sciences and Division of Applied Sciences \\ Harvard University, Cambridge, Massachusetts
}

\begin{abstract}
Three-dimensional finite element calculations are employed to study interactions in space and time between the creeping segment of the San Andreas fault in central California and the adjacent currently locked zones of the 1857 and 1906 great earthquakes. Vertically, the model consists of an elastic upper crust over a Maxwell viscoelastic region, representing the entire lower crust or a narrower horizontal detachment layer, and a stiffer and more viscous upper mantle. The crust has a single vertical fault extending to the top of the mantle at $25 \mathrm{~km}$ depth. In zones along strike corresponding to the 1857 and 1906 events, the top $12.5 \mathrm{~km}$ of the fault is locked against slip, except in great earthquakes. Below the locked zones and everywhere along the creeping region between them, the fault is freely slipping. The model parameters are compatible with seismological and geological observations, and with a ratio of Maxwell relaxation time to the relaxing layer thickness in the range 1 to $2 \mathrm{yr} / \mathrm{km}$, as established by $\mathrm{Li}$ and Rice (1987) and Fares and Rice (1988) based on fits to geodetic data along the San Andreas fault. An imposed constant far field shear motion and periodic 1857-and 1906 - type earthquakes generate slip rates along the creeping fault segment that evolve in time throughout the entire earthquake cycle. Shortly after an adjacent great earthquake, slip rates in the creeping zone are higher than the far field velocity, while later in the cycle they are lower. Hence, time dependency should be accounted for when measurements of fault slip are used to estimate the plate motion. If Parkfield earthquakes are a response to a time dependent loading of the type simulated here, their recurrence interval would tend to lengthen with time since the 1857 event. Thus, the hypothesis of characteristic periodic earthquakes at Parkfield may not provide the best estimate of the occurrence time of the next event. Using, for example, the statistics of past events and assuming that Parkfield earthquakes are a response to a slip deficit near Middle Mountain, and that the elastic crustal layer is $17.5 \mathrm{~km}$ thick, we find that the next event is predicted for about $1992 \pm 9$ years if the lower crust is a $7.5 \mathrm{~km}$ thick layer having a material relaxation time of 15 years, and $1995 \pm 11$ years if the $7.5 \mathrm{~km}$ thick lower crust is characterized by a relaxation time of 7.5 years. These values may be compared to the $1988 \pm 7$ years estimate based on periodicity in time. The modeling results also indicate that the interaction between the 1857 and 1906 rupture zones is small.
\end{abstract}

\section{INTRODUCTION}

The San Andreas Fault (SAF) rupture zones of the great 1857 Fort Tejon and 1906 San Francisco earthquakes (Figure 1) are presumed to slip only in great events, at least at depths less than approximately 10 to $12 \mathrm{~km}[$ e.g., Carlson et al., 1979]. Currently these regions are locked against slip. In contrast, the $170 \mathrm{~km}$ section of the fault in central California between those locked segments is characterized by a more-orless continuous right-lateral creep-slip motion, with surface creep rates tapering towards zero at the ends of the segment, one somewhat NW of San Juan Bautista and the other SE of Parkfield (see Figure 2 and references in the caption). Those two end regions are also the sites of moderate earthquakes with recurrence intervals of order 20 years, much shorter than estimated average recurrence intervals of order 150 years for the locked 1857 and 1906 rupture zones.

If the upper and middle crust respond elastically to the great earthquakes, then it must be assumed that the occurrence of those great events causes stress transfer to the NW and SE, along the strike of the SAF. Stress transfer between different fault segments (as well as off the fault) is enhanced by the stable shearing (viscous flow) in the hotter lower crust,

Copyright 1993 by the American Geophysical Union.

Paper number 92JB02154.

0148-0227/93/92JB-02154\$05.00 implied by the lack of seismicity below the upper $15 \mathrm{~km}$ or so of the crust. It thus seems inevitable that the slip rates along the central California SAF creeping zone must exhibit some transients in response to the adjacent great earthquakes. The study of slip rate transients in the great earthquake deformation cycle is important for understanding how the time average slip rate of $32-34 \mathrm{~mm} / \mathrm{yr}$, observed over recent years (that for 1966 to 1980 is shown in Figure 2) near the center of the creeping zone, relates to the portion $\mathrm{V}_{\mathrm{pl}}$ of the long term plate velocity that is accommodated along the San Andreas fault.

The nature and time duration of loading slip rate transients, as sensed near the ends of the creeping zone at Parkfield and San Juan Bautista, should also be important for assessing the reliability by which dates of prior moderate earthquakes at those locations can be used to predict the occurrence times of future events. For example, it has been suggested that moderate (M6) earthquakes have recurred at Parkfield on average every 22 years since the great 1857 earthquake [Bakun and McEvilly, 1984], although the last three events (1922, 1934, 1966) define recurrence intervals of 12 and 32 years and the completeness of the Parkfield earthquakes catalogue in the late 1800 s and early 1900 s has been questioned [Toppozada, 1985; Toppozada et al., 1990]. Clearly, the focus on an average recurrence interval presupposes that the local crustal loading rates and processes leading to each Parkfield event are essentially identical for events in the late $1800 \mathrm{~s}$ and for those in the mid and late 


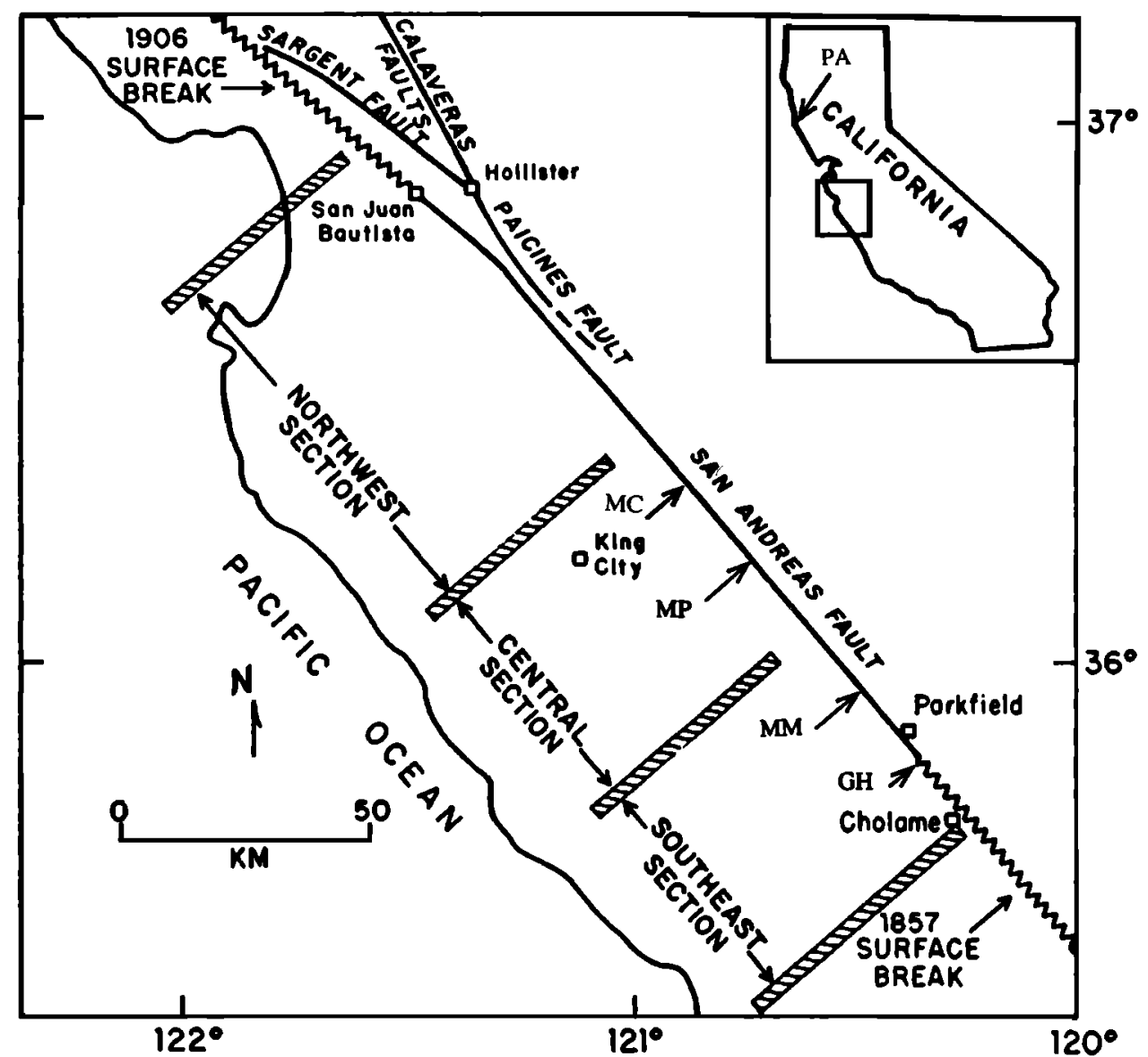

Fig. 1. Map of the San Andreas fault in central Califomia. GH, MM, and MP mark, respectively, the locations of Gold Hill, Middle Mountain, and Monarch Peak. MC, located roughly in the middle of the creeping zone, shows the NW boundary of the finite element mesh used in this paper. PA in the inset map marks the location of Point Arena, referred to in Figure 2. Modified from Burford and Harsh [1980].

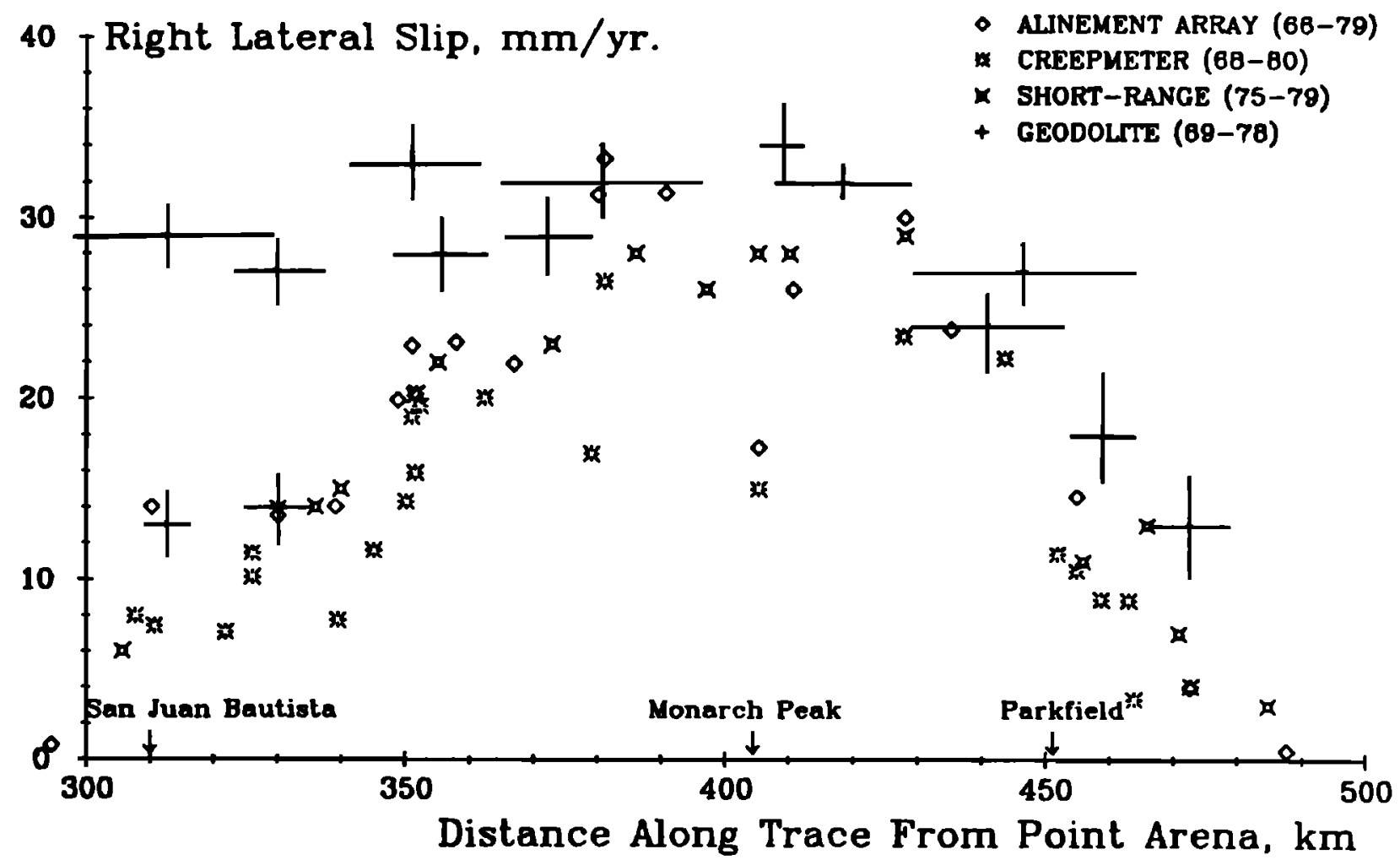

Fig. 2. Estimates of slip rates along the San Andreas fault from San Juan Bautista to Cholame for the period 1966 to 1980 (from Tse et al., [1985], after Burford and Harsh, [1980]; Lisowski and Prescott, [1981]; Schultz et al., [1982]). 
1900s, apart from a (not yet understood) scatter about the mean. This may not be a valid assumption if there are significant long term transients in crustal loading from the adjacent great earthquakes.

Our goal in the present paper is to model the along-strike interactions of the different SAF segments and hence to quantify the extent and time scale of the expected transients. A simple first model of these effects was studied by Dmowska et al. [1985]. They assumed that steady mantle motion, compatible with overall plate velocities, is transmitted to a viscoelastic lower crustal asthenosphere. Elastic upper crustal plates were joined along a fault of which one section, the central California creeping zone, was creeping at constant stress while the remainder (zones of the great 1857 and 1906 earthquakes) was locked except at times of great earthquakes. Their analysis employed a generalization of the Elsasser model [Rice, 1980; Lehner et al., 1981] in which Maxwell viscoelastic, rather than purely viscous, response is assumed for the asthenospheric-like layer underlying an elastic surface plate. Such a model, with special treatment of the fault zone as a partly-cracked section in an elastic plate, was used by $L i$ and Rice [1987] to model crustal straining associated with great earthquake cycles along the presently locked portions of the SAF. The $\mathrm{Li}$ and Rice modelling was simplified compared to the model suggested by Dmowska et al. since it assumed no variation of stressing conditions along the strike of the fault. Dmowska et al. [1985] reported preliminary results of the analysis of along-strike heterogeneity and subsequently, Rice and Dmowska [1986, 1987] reported increasingly more elaborate analyses, based also on the Elsasser model. The Dmowska et al. [1985] and Rice and Dmowska [1986, 1987] analyses, however, employed severe approximations in order to solve the Elsasser model in a form that allowed along-strike variation (e.g., the locked fault zone depth had to be equated to the entire elastic plate thickness). In addition, subsequent two-dimensional finite-element analyses by Fares and Rice [1988] of the same basic physical model as treated by Li and Rice [1987] showed that the Elsasser model itself was not a very good approximation to response in the early part of the earthquake cycle.

In view of the above, it appears that a proper study of interactions between the creeping zone and the adjacent locked segments of great earthquakes requires a fully threedimensional treatment. This is done in the present paper via 3D finite element calculations for a fault embedded in a layered elastic/viscoelastic medium. Our model parameters are constrained by seismological, rheological, and thermal considerations, and by the previous modeling and geodetic data fits of Li and Rice [1987] and Fares and Rice [1988]. The modeling results indicate that constant far field plate motion and a periodic sequence of 1857- and 1906- type earthquakes generate along the creeping SAF zone slip rates that are strongly non-uniform in time. Early in the cycle fault slip rates are higher than the far field velocity, while later in the cycle they are lower. It thus appears that short time geodetic measurements along the fault may not, in general, be sufficient for an accurate estimate of the plate motion.

The analysis results suggest that earthquakes would tend to cluster in time early in the deformation cycle when the loading rate is high, and to cluster in space near the location of previous great events. If Parkfield earthquakes are a response to the simulated time dependent loading, their recurrence interval would tend to lengthen with time since the 1857 event. Using the statistics of past events we find that predictions of the next Parkfield earthquake based on timedependent slip deficit are delayed with respect to the estimate based on average earthquake recurrence time.

Following a large earthquake an anelastic deformation zone spreads along and away from the fault in a diffusion-like manner. Progress of the anelastic deformation zone may trigger additional deformation events at large distances from the original shock. The modeling results indicate that the interaction between the 1857 and 1906 rupture zones is small.

\section{MODELING CONCEPTS}

We assume that the upper and middle crust adjoining the San Andreas fault responds elastically to tectonic stressing and can be modeled as elastic surface plates loaded by basal shear drag (Figure 3) from an underlying, essentially steady, ongoing flow pattern in the upper mantle [e.g., Dmowska et al., 1985; Li and Rice, 1987; Fares and Rice, 1988]. The shear drag stresses are transmitted to the surface plates through a viscously relaxing asthenospheric layer which, for reasons to be summarized, can be identified with the lower crust or perhaps a detachment layer within the crust.

Along the great earthquake segments, the fault in the crust is assumed to be locked over some depth range $\mathrm{L}$, of order 10 to $15 \mathrm{~km}$, except during seismic slipping. At greater crustal depths, the fault is presumed to displace continuously due to shear in a broadening and increasingly ductile lower fault zone. In contrast, along the central portion of the creeping zone the fault is assumed to displace continuously at all crustal depths. The situation towards the ends of the creeping zone is more complex. This is evident from modeling of geodetic data at Parkfield [Stuart et al., 1985; Tse et al., 1985; Segall and Harris, 1986, 1987; Harris and Segall, 1987], which suggests a submerged locked zone with continuously slipping regions above and below. In the present modeling of along-strike interactions we simplify matters by assuming that there is no locked zone all along the creeping SAF segment. This choice averages out the occasional moderate earthquakes near San Juan Bautista and Parkfield and lumps them into the creep-slip rate towards the ends of the creeping zone.

Li and Rice [1987] used the generalized Elsasser procedure

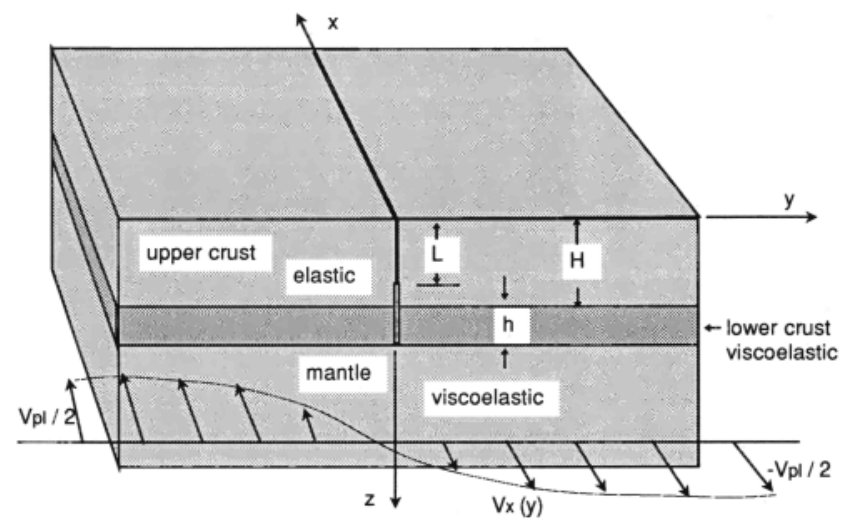

Fig. 3. A conceptual model for crustal structure and loading following Dmowska et al. [1985], Li and Rice [1987] and Fares and Rice [1988]. An elastic upper crust of thickness $H$ overlies a viscoelastic lower crust of thickness $h$. A vertical fault, extending from the surface to a depth $L$, is locked except during earthquakes. The crust is loaded by an upper mantle shear flow that accommodates the relative plate motion. 
to study a $2 \mathrm{D}$ version of the model shown in Figure 3. They chose a locking depth, a far field plate velocity, and an earthquake cycle time from seismic and geologic evidence $(\mathrm{L}$ $=9$ to $11 \mathrm{~km}$ based on earthquake nucleation depths along the San Andreas system, $\mathrm{V}_{\mathrm{pl}}=35 \mathrm{~mm} / \mathrm{yr}, \mathrm{T}=160$ years). Their remaining model parameters were the elastic layer thickness $H$ and the ratio $\tau_{r} / h$, where $\tau_{r}$ and $h$ are, respectively, the relaxation time and thickness of a Maxwellian viscoelastic channel underlying the elastic layer (Figure 3 ). The parameters $H$ and $\tau_{\mathrm{r}} / \mathrm{h}$ were constrained by fitting predictions of their model to strain rate data along the San Andreas fault as a function of time since the last great earthquake [Thatcher, 1983]. Fares and Rice [1988] performed full 2D finite element calculations for the same model and data used by $L i$ and Rice [1987]. The preferred range of parameters emerging from these two works are $\mathrm{H}=15-30 \mathrm{~km}$ and $\tau_{\mathrm{r}} / \mathrm{h}=1-2 \mathrm{yr} / \mathrm{km}$. Neither of the quantities $\tau_{r}$ and $h$ were constrained independently; they appear in the Elsasser model only as that ratio, and Fares and Rice [1988] found that their finite element results after a fifth or so of the earthquake cycle did not vary much with factor of 2 or more changes in $\tau_{\mathrm{r}}$ and $\mathrm{h}$ so long as their ratio was fixed.

Oppenheimer and Eaton [1984] used earthquake travel times to infer depths of the Moho along the SAF from Carrizo Plain, slightly SE of the SAF creeping segment, to Point Arena along the 1906 rupture zone. Their results suggest a Moho depth, and hence crustal thickness, of slightly greater than $24 \mathrm{~km}$ over most of this $500 \mathrm{~km}$ range, with local thinning toward $23 \mathrm{~km}$ near Point Reyes, just NW of San Francisco, and thickening toward $26 \mathrm{~km}$ at the ends of the studied region. In this work we keep the crustal thickness $(\mathrm{H}+\mathrm{h}$ in Figure 3) constant at $25 \mathrm{~km}$.

Representative San Andreas geotherms suggest that the lower section of the crust, say, below $20 \mathrm{~km}$, should be above approximately $450^{\circ} \mathrm{C}$ [Lachenbruch and Sass, 1973]. While that may still not be hot enough to allow solid state dislocation creep flow, we assume that some relaxation process, possibly based on pore-fluids [Linker and Rice, 1991], does take place in the lower crust, as argued from the absence of seismicity below $15 \mathrm{~km}$ and from the requirement of some form of deep relaxation at or near the roots of seismic fault zones in fitting geodetic data. Thus we assume that the crust is divided into an upper elastic layer of a thickness $\mathrm{H}=$ $17.5 \mathrm{~km}$, and a lower viscoelastic channel with a ratio $\tau_{\mathrm{r}} / \mathrm{h}=$ 1-2 $\mathrm{yr} / \mathrm{km}$. Taking, for simplicity, this channel to occupy the entire crust below $17.5 \mathrm{~km}$ (it could also be a narrower detachment channel), we give it a thickness $h=7.5 \mathrm{~km}$ and thus use lower crust Maxwell relaxation times of 7.5 and 15 years.

\section{ANALYSIS}

Figure 4 shows a 3D block model consisting of a $17.5 \mathrm{~km}$ thick elastic upper crust, a $7.5 \mathrm{~km}$ viscoelastic lower crust, and a more viscous and elastically stiffer viscoelastic upper mantle. The lower crust and upper mantle are governed by a Maxwell viscoelastic constitutive law characterizing a series arrangement of elastic and viscoelastic elements, $\dot{\gamma}=\dot{\tau} / \mu+\tau / \eta$, where $\gamma$ and $\tau$ are strain and stress, respectively, the over dots denote derivatives with respect to time, $\mu$ and $\eta$ are rigidity and viscosity, respectively, and the ratio $\tau_{\mathrm{r}}=\eta / \mu$ defines a material relaxation time. Kinematically imposed boundary

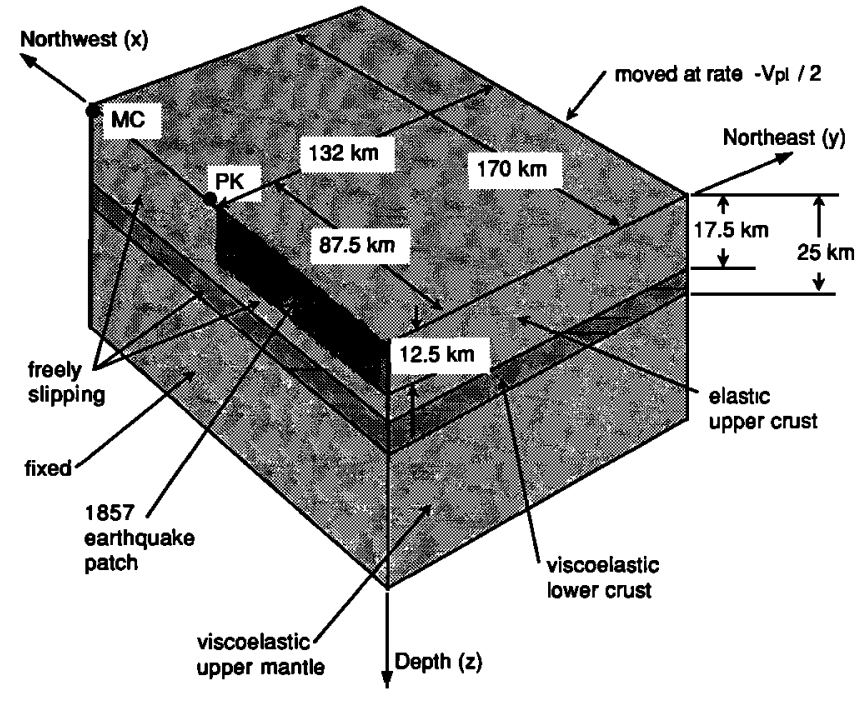

Fig. 4. A block model for the finite element calculations. See explanation in text.

conditions drive the model away from equilibrium. The resulting stresses and displacements are calculated by the finite element code ABAQUS [Hibbitt, Karlsson and Sorensen, Inc., 1989]. Cross-sections of the finite element mesh used in the calculations are shown in Figures 5a and 5b.

During the analysis the right (NE) block face is constrained to move rigidly at a constant rate of $17.5 \mathrm{~mm} / \mathrm{yr}(1 / 2$ the far field plate velocity). The upper crustal region at the left (SW) block face models the SAF. It contains a great earthquake patch on which we impose a staircase slip history (see Figure 6a, top trace). The earthquake patch extends from the surface to a depth of $12.5 \mathrm{~km}$. Underneath and $\mathrm{NW}$ of the earthquake patch the SAF is freely slipping. The lower crustal region of the left model face is freely slipping, while the upper mantle region there is held fixed at zero displacement.

For the mantle, we choose $\mu$ to be twice that of the crust and $\eta$ to be 20 times that of the less viscous lower crust layer $(\eta / \mu$ for the mantle is 75 years). This makes the mantle mechanically much stronger than the overlying crust and causes its shear flow, in response to the imposed steady driving boundary conditions, to be at most only modestly affected by the crustal earthquakes above. $\mathrm{Li}$ and Rice [1987] showed that this circumstance causes the crustal response, in the presence of a viscoelastic asthenospheric layer, to become (in a steady state of repeated earthquakes) independent of the detailed distribution of mantle shear that accommodates the relative plate motion. The boundary conditions and relatively high viscosity of the upper mantle generate a steady basal shear profile like that of Figure 3, but now approximately uniform over the $132 \mathrm{~km}$ mantle half-width that we model. The response of the less viscous lower crust, with a freely slipping zone at the downward continuation of the SAF, to abrupt earthquake occurrences imposes a spaceand time- dependent basal shear load on the elastic upper crust. In addition, the upper crust is loaded by a steady elastic stress increment due to the ongoing far field motion.

The boundary conditions on the SE and NW block end faces are periodic, implying mirror extensions of the model in both directions. Thus, our calculations correspond to a $175 \mathrm{~km}$ long southeastern (1857) rupture zone, a $165 \mathrm{~km}$ long central creeping segment, and a $175 \mathrm{~km}$ long northwestern (1906) 


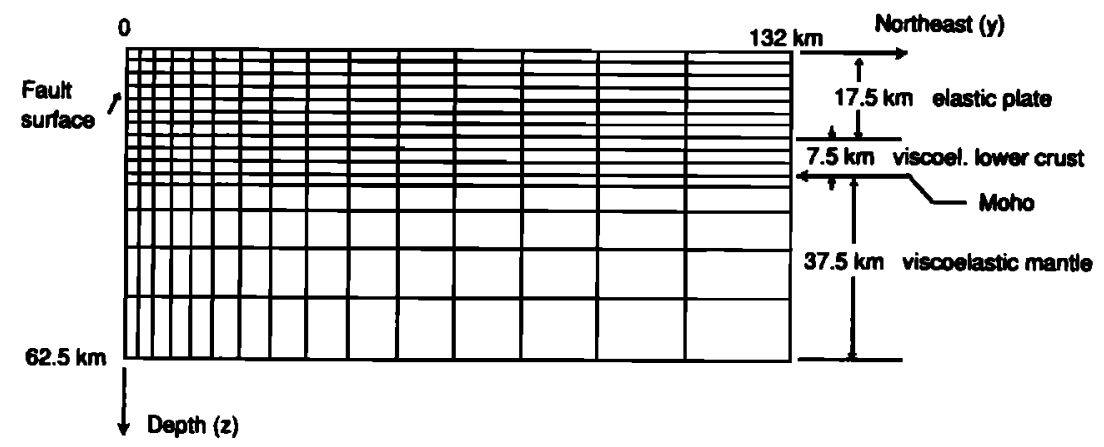

Fig. 5a. View of cross section normal to fault of the finite element mesh used in the calculations. Density of elements increases toward the fault and the earth's surface.

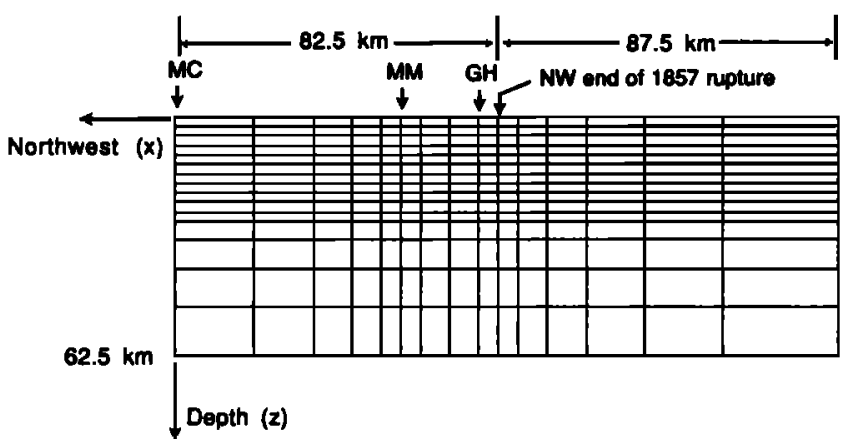

Fig. $5 b$. View along the fault of the finite element mesh used in the calculations.

rupture zone, all repeated periodically to the NW and SE. With a proper combination of slip histories on the earthquake patch and symmetric/antisymmetric boundary conditions on the end faces (see Appendix), the block shown in Figure 4 can be used to model the central California crustal deformation field due to both the 1857 and 1906 earthquakes.

Figure 6a presents 900 years of model right-lateral slip

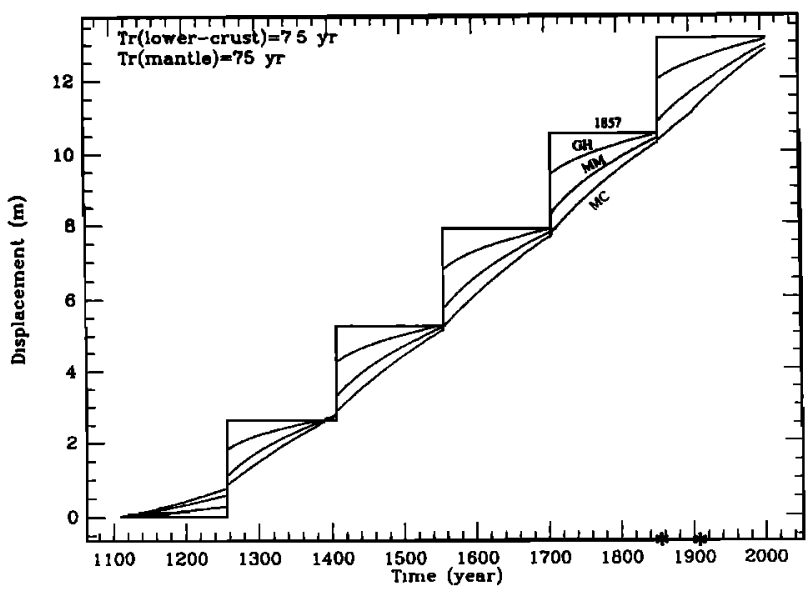

Fig. 6a. Model right-lateral slip at four San Andreas fault sites. Top curve shows imposed history on the 1857 earthquake patch. Other curves show calculated displacements. Rigidities of upper crust, lower crust, and upper mantle are $3 \times 10^{4} \mathrm{MPa}, 3 \times 10^{4} \mathrm{MPa}$, and $6 \times 10^{4} \mathrm{MPa}$, respectively. Viscosities of lower crust and upper mantle are $6.72 \times 10^{12} \mathrm{MPa} s$ and $1.35 \times 10^{14} \mathrm{MPa} \mathrm{s}$, respectively. Lower crust parameters correspond to relaxation time $\tau_{\Gamma}=7.5$ years and ratio $\tau_{\Gamma} / \mathrm{h}=1 \mathrm{yr} / \mathrm{km}, \mathrm{h}=7.5 \mathrm{~km}$ being the lower crust thickness. Stars on horizontal axis mark times of the 1857 and 1906 earthquakes. along the Earth's surface at four SAF sites; this includes a conditioning period for the analyses discussed below. The upper trace gives the kinematically imposed periodic earthquake sequence at the 1857 fault patch. The other three curves show calculated displacements at the SE end of the Parkfield asperity NW of the 1857 locked zone (GH, Gold Hill), the Parkfield earthquake nucleation site (MM, Middle Mountain), and the NW end of the finite element mesh, near the middle of the creeping zone (MC). The first 750 analysis years constitute a conditioning period. The transients associated with the initial model conditions have largely decayed after about $\mathbf{4 5 0}$ analysis years, and during the final two or three earthquake cycles the model response is nearly periodic. For simplicity, the northwestern and southeastern locked sections are ruptured at identical times during the conditioning period. Figure $6 \mathrm{~b}$ shows expanded displacement curves for the last 200 analysis years. Variations of the displacement slopes with time indicate the anelastic timedependent component in the tectonic deformation rates at the various SAF sites. The effect increases toward the 1857 rupture area, implying that the Parkfield asperity may experience significant transients during an 1857-type earthquake deformation cycle. We note that the 1906 earthquake has little effect on the deformation field at MM and GH.

Taking time derivatives in Figure 6 we compute slip velocities $\mathrm{V}$ along the SAF. The results for the last 150 analysis years, normalized by the far field plate motion, are shown in Figure 7. We observe that everywhere along the $\mathrm{SAF}$, the velocities are non-uniform in time throughout the

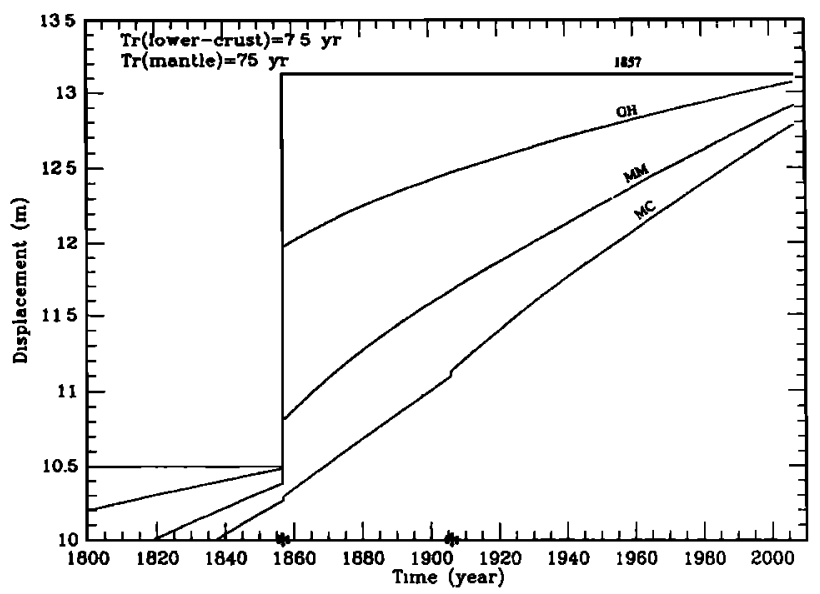

Fig. 6b. Last 200 years of Figure $6 a$. 


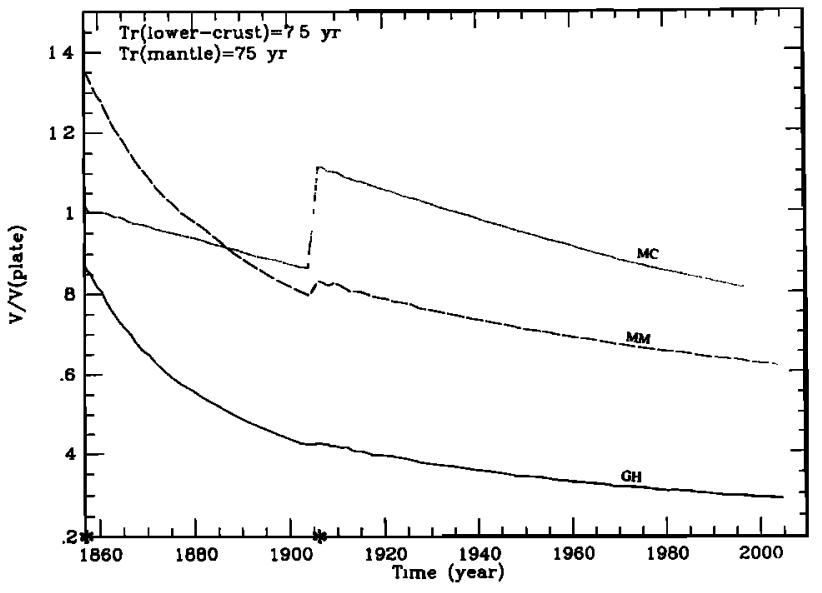

Fig. 7. Slip rates along the San Andreas fault, nomalized by the far field plate motion. Model parameters are the same as in Figure 6. Stars on horizontal axis mark times of the 1857 and 1906 earthquakes.

entire earthquake deformation cycle. Early in the cycle the slip velocities are higher than the far field rate in some places while later they are always slower. The slip rate at every point averages over a long time to $\mathrm{V}_{\mathrm{pl}}$; this is evident from Figure $6 \mathrm{a}$ but does not show in the plots of Figure 7, in part because delta function spikes in $\mathrm{V}$ corresponding to coseismic slip at the times of the 1857 and 1906 earthquakes are not shown, and in part because the conditioning does not precisely coincide with the slip since 1857 in the northwestern locked zone. Thus, if our viscoelastic parameters for this calculation are in a range that reasonably represents conditions along the SAF, it is clear that short time geodetic measurements along the fault do not provide, in general, accurate estimates of the far field plate motion. In particular, slip rates near the ends of the creeping zone (e.g., $\mathrm{GH}, \mathrm{MM}$ ) vary strongly throughout the entire earthquake cycle, while simulated slip rates near the middle of the creeping zone (e.g., MC) during most of the earthquake cycle (i.e., a few tens of years away from the occurrence time of a great earthquake) differ from the far field motion by an amount similar to error values of current geodetic measurements. Figure 7 indicates that the loading rate of an asperity coinciding with the Parkfield patch will vary significantly during an 1857-type earthquake cycle. Thus, as suggested by Dmowska et al. [1985], it is not expected that Parkfield earthquakes will be equally spaced in time. Instead we anticipate frequent failures at the beginning of the cycle and decaying earthquake activity as the cycle matures, i.e., we expect Parkfield earthquakes to cluster in time following a large 1857-type event. The 1906 earthquake is seen to change significantly the slip rate near the middle of the SAF creeping segment (MC), but to have little effect at MM and GH near the southeastern end of the creeping zone.

The present finite element calculations allow comparison with the Rice and Dmowska [1986, 1987] estimates, based on the generalized Elsasser model, of time dependent slip at MM and MC. Their analysis gives results for values of $H=15,21$, and $30 \mathrm{~km}$, and for values of a time parameter $t_{r}$ (corresponding to $\pi^{2} \mathrm{H} \tau_{\mathrm{r}} / 16 \mathrm{~h}$ in our notation) of 10,13 and 16 years. Their results for $H=15 \mathrm{~km}$ and $t_{\mathrm{r}}=10$ years, and for $\mathrm{H}=21 \mathrm{~km}$ and $\mathrm{t}_{\mathrm{T}}=13$ years, correspond, respectively, to $\tau_{\mathrm{r}} / \mathrm{h}=1.1$ and $1.0 \mathrm{yr} / \mathrm{km}$, and thus may be compared to our $3 \mathrm{D}$ finite element calculations with $\mathrm{H}=17.5 \mathrm{~km}$ and $\tau_{\mathrm{r}} / \mathrm{h}=1$ $\mathrm{yr} / \mathrm{km}$. The analysis based on the Elsasser model predicts that the slip rate at MM diminishes between 1857 (just after the large earthquake) and the year 2000 by about $33 \%$ in the first case $(\mathrm{H}=15 \mathrm{~km})$ and by about $42 \%$ in the second $(\mathrm{H}=21 \mathrm{~km})$, whereas the present and presumably more accurate finite element results show an even greater decrease of $54 \%$ for comparable rheological and other model parameters.

The lower crust viscosity used in calculating the results of Figures 6 and 7 corresponds to a relaxation time $\tau_{r}=7.5$ years, or a ratio $\tau_{\mathrm{r}} / \mathrm{h}=1 \mathrm{yr} / \mathrm{km}$. As mentioned earlier, Fares and Rice [1988], in performing finite element calculations for range of cases studied by $L i$ and Rice [1987], suggested that $\tau_{\mathrm{r}} / \mathrm{h}$ for the SAF is in the range of $1-2 \mathrm{yr} / \mathrm{km}$. The constraint on $\tau_{\mathrm{r}} / \mathrm{h}$ is, however, not very strong. The Fares and Rice work includes fits of geodetic data for the Palmdale area, along the 1857 rupture [e. g., Lisowski et al., 1991a], while the choice of model parameters made by Li and Rice [1987], namely $\tau_{\mathrm{r}} / \mathrm{h}=1.0$, prior to availability of that data set also gave a good fit [Segall, 1991]. Recently, Lyzenga et al. [1991], using 2D finite element analysis, found in their linear Maxwell model an acceptable fit for the same (Palmdale) data set with $\tau_{\mathrm{r}} / \mathrm{h} \approx 3$ $\mathrm{yr} / \mathrm{km}$ [M. F. Linker, personal communication, 1992]. To illustrate effects of the lower crust viscosity on the model response we examine fault slip rates calculated using $\tau_{\mathrm{r}}=15$ years or $\tau_{\mathrm{r}} / \mathrm{h}=2 \mathrm{yr} / \mathrm{km}$ (Figure 8). As expected, increasing viscosity decreases the stress transfer along the fault. Thus the magnitude and maximum occurrence of transient effects in Figure 8 are reduced and delayed with respect to those of Figure 7 .

Following an earthquake the co-seismic stresses shed into the lower crust are relaxed by viscous flow, resulting in a diffusion-like progress of anelastic deformation zone along and away from the fault. Figure 9 shows a fault-normal profile of fault-parallel displacements along the Earth's surface at various times throughout the earthquake cycle for the $\tau_{\mathrm{r}} / \mathrm{h}=1$ $\mathrm{yr} / \mathrm{km}$ case. The profile extends from the 1857 rupture zone, $22.5 \mathrm{~km} \mathrm{SE}$ of $\mathrm{GH}$, to the far field. The co-seismic displacement profile is characterized by large spatial gradients. This results in large strains and stresses which decay in time through viscous flow in the lower crust. Figure 10 shows the time evolution of right-lateral surface slip along the SAF, from GH in the SE to San Juan Bautista in the NW. The 1857 earthquake generates noticeable co-seismic

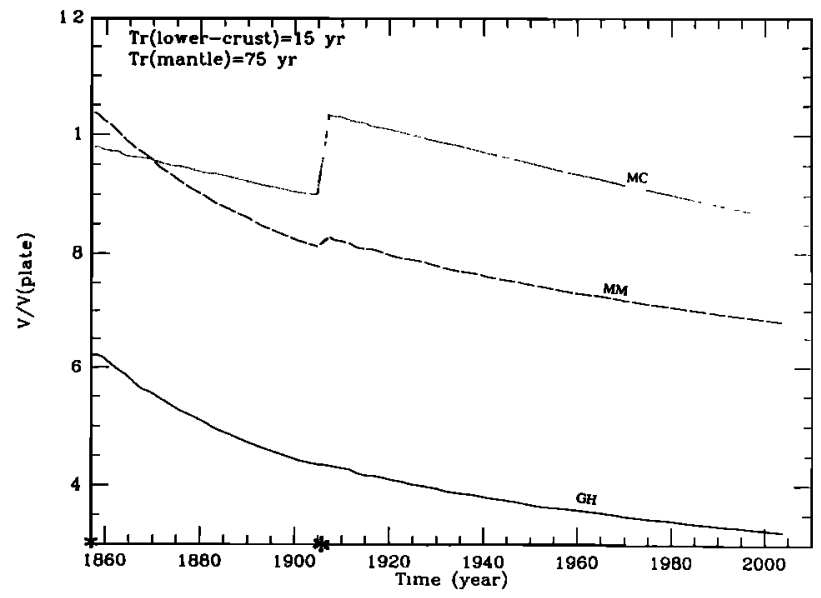

Fig. 8. Same as Figure 7 for lower crust viscosity $1.35 \times 10^{13} \mathrm{MPa}$. Here $\tau_{\mathrm{r}}=15$ years and $\tau_{\mathrm{r}} / \mathrm{h}=2 \mathrm{yr} / \mathrm{km}$. 


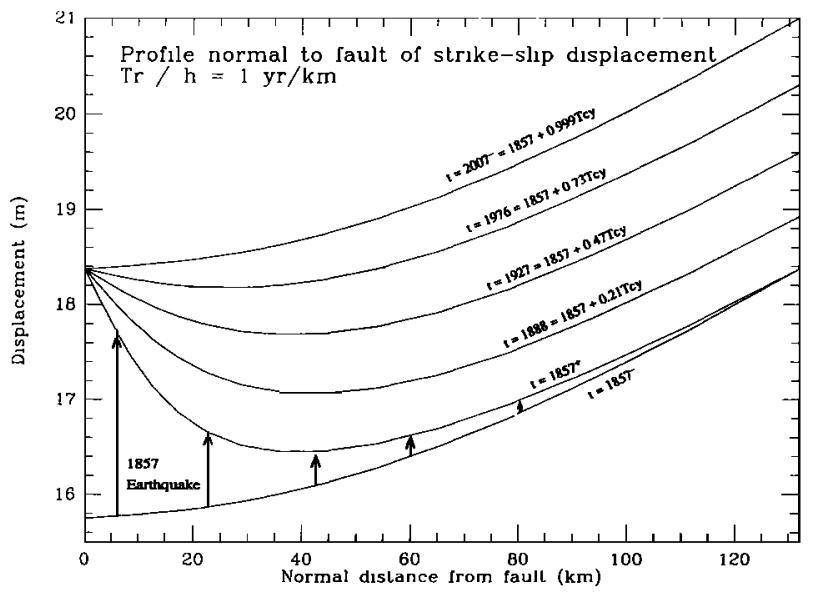

Fig. 9. Fault-parallel displacement profile normal to the San Andreas fault from the 1857 patch, $22.5 \mathrm{~km} \mathrm{SE}$ of $\mathrm{GH}$, to the far field. Absolute times are indicated by $t$. Model parameters are same as in Figure 6 .

displacements at the southeastern $60 \mathrm{~km}$ or so section of the creeping SAF segment. The 1906 event generates similar displacements at the northwestern most $60 \mathrm{~km}$ or so creeping zone. These coseismic steps occur because we model the entire creeping zone as being freely slipping, and thus being unable to sustain any increase in stress caused by the great ruptures. In reality, we expect these coseismic steps to occur mostly as an accelerated slip rate over a time scale that is short relative to that over which appreciable effects occur due to the lower crustal relaxation that we have analyzed. The large displacement gradients formed along strike (Figure 10) by the 1857 and 1906 earthquakes are relaxed with time via viscous flow in the lower crust. We note that the anelastic strain field propagating away from the rupture area may trigger associated deformation events.

\section{DISCUSSION}

We performed 3D finite element simulations of the SAF earthquake deformation cycle in the vicinity of the central California creeping zone using an earth model consisting of an elastic upper crust overlying a viscoelastic lower crust and upper mantle, and a fault having great 1857- and 1906- type rupture zones and a central creeping segment. The calculated fault slip rates vary in time throughout the entire earthquake

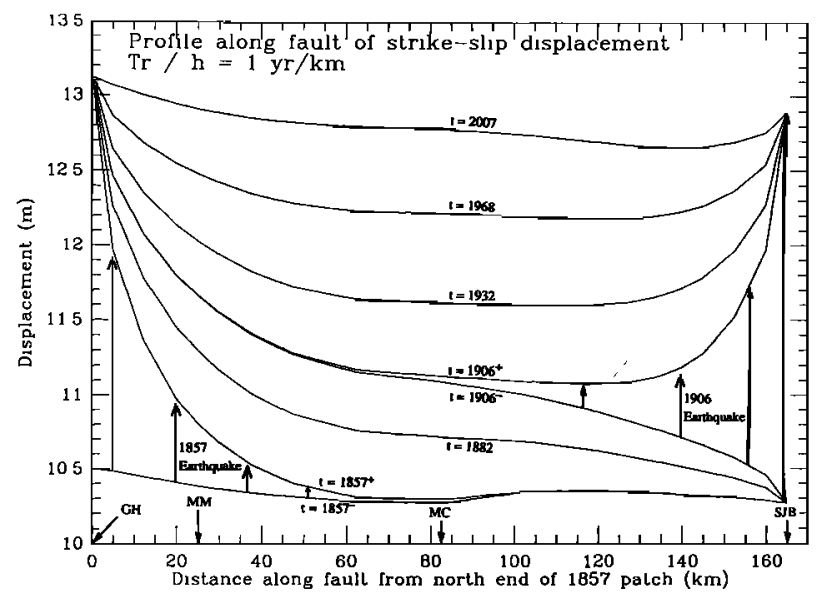

Fig. 10. Right-lateral slip profile along the San Andreas fault. Absolute times are indicated by t. Model parameters are same as in Figure 6. cycle, in a manner of diminishing strain rate along the SAF with time since a great earthquake. This is similar to what is indicated by the data of Thatcher [1983] for the 1906 and 1857 rupture zones. We note that the usual geodetic modeling of inter-earthquake deformation using buried dislocations in an elastic half space [e.g., Prescott, et al., 1979; McGarr et al., 1982; Savage, 1983; King and Savage, 1984] ignores time dependent features of crustal response. The generally agreed upon thermal arguments for the lack of seismicity below the top $15 \mathrm{~km}$ or so of the crust require, however, that there be relaxation deep in the crust. These arguments involve transition with increase of temperature, and depth, to ductile creep flow [e.g., Sibson, 1982] or possibly first to inherently stable velocity-strengthening friction [Tse and Rice, 1986]. The essential point is that the hot deep crustal material is unable to support stress on the time scale of the earthquake cycle and, instead, deforms under far smaller stress than that required for brittle elastic response to tectonic loading.

Our model results can be used in conjunction with observed fault slip rates to provide an estimate of the plate velocity. Geodolite measurements across the SAF at MC for a time window centered around 1975 give $\mathrm{V}_{M C}(1975$, geodolite $)=$ 32-34 mm/yr (Figure 2). Our simulated time-dependent slip rates at MC for 1975 (Figures 7 and 8) indicate ratios of 0.90 and 0.92 for $\mathrm{V}_{\mathrm{MC}}(1975) / \mathrm{V}_{\mathrm{pl}}$, assuming lower crust relaxation times $\tau_{\mathrm{r}}=7.5$ and 15 years, respectively. Combining the above ratios with the geodolite data we estimate the plate velocity as $\mathrm{V}_{\mathrm{pl}}=35.5-37.8 \mathrm{~mm} / \mathrm{yr}$ for $\tau_{\mathrm{r}}=7.5$ years, and $\mathrm{V}_{\mathrm{pl}}$ $=34.8-36.9 \mathrm{~mm} / \mathrm{yr}$ if $\tau_{r}=15$ years. These results and corresponding estimates based on short range geodetic observations are summarized in Table 1. Using now the range of inferred plate velocities together with our model results for $\mathrm{V}_{\mathrm{MM}}\left(\right.$ 1975) $/ \mathrm{V}_{\mathrm{pl}}$ (Figures 7 and 8) we can estimate the fault slip rate at MM that would have occurred in the absence of the Parkfield asperity. This gives ideal, freely-slipping fault, velocities at $\mathrm{MM}$ in the range $\mathrm{V}_{\mathrm{MM}}(1975)=18.8-26.6 \mathrm{~mm} / \mathrm{yr}$ (see Table 1). Measured slip rates at MM for a period centered on 1975 are $12-18 \mathrm{~mm} / \mathrm{yr}$ (Figure 2). Combining the observed slip rates with the $100-200 \mathrm{~mm}$ co-seismic slip at MM during the 1966 Parkfield earthquake, distributed over an average earthquake repeat time of 22 years, we obtain 16.5-27 $\mathrm{mm} / \mathrm{yr}$, in agreement with our model prediction.

Perhaps it should be emphasized that measurements of the time-dependent effects discussed here require geodetic surveys of the fault zone proper with high spatial and temporal resolution. Thatcher [1979], for instance, modeled slip rates along the SAF creeping zone for the time interval 18851962, spanning the occurrence time of the 1906 earthquake, in terms of a constant velocity block motion. His data, however, are taken as far as $60 \mathrm{~km}$ from the fault trace (note that $\mathrm{V} \rightarrow \mathrm{V}_{\mathrm{pl}} / 2$ as one moves to the far field) and are grossly averaged in time and space. Still, inverting the geodetic data (primary arc and astronomical azimuth lines) separately for the time periods 1885-1923 and 1923-1962, Thatcher [1979] obtained block motions that are different by $2 \pm 4 \mathrm{~mm} / \mathrm{yr}$. Averaging our model results in space along the SAF (a less severe space averaging than the along- and off- fault average in Thatcher's work) and in time as is done in Thatcher [1979], we obtain a difference of $3 \mathrm{~mm} / \mathrm{yr}$ in the average simulated slip rates for the pre- and post- 1923 periods. Savage [1978] shows the astronomical azimuths data used by Thatcher 
TABLE 1. Estimates of Plate Velocity and Ideal (Freely Slipping Fault) Slip Rates at MM, Using Geodetic Measurements (Figure 2) and Calculated Time-Dependent Slip Rates (Figures 7 and 8)

\begin{tabular}{ccccc}
\hline & \multicolumn{2}{c}{ From Model Output at 1975} & $\begin{array}{c}\text { Inferred } \mathrm{V}_{\mathrm{pl}} \\
\mathrm{mm} / \mathrm{yr}\end{array}$ & $\begin{array}{c}\text { Ideal } \mathrm{V}_{\mathrm{MM}} \\
\mathrm{mm} / \mathrm{yr}\end{array}$ \\
\hline$\tau_{\mathrm{r}}(\mathrm{lc})=7.5$ years & 0.90 & 0.69 & $35.5-37.8^{*}$ & $24.5-26.1^{*}$ \\
& & & $27.2-35.0^{\dagger}$ & $18.8-24.1^{\dagger}$ \\
$\tau_{\mathrm{r}}(\mathrm{lc})=15$ years & 0.92 & 0.72 & $34.8-36.9^{*}$ & $25.1-26.6^{*}$ \\
& & & $26.6-34.2 \dagger$ & $19.1-24.6 \dagger$ \\
\hline
\end{tabular}

* Using geodolite data for $\mathrm{V}_{\mathrm{MC}}(1975)=32-34 \mathrm{~mm} / \mathrm{yr}$.

$\dagger$ Using short-range data for $\mathrm{V}_{\mathrm{MC}}(1975)=24.5-31.5 \mathrm{~mm} / \mathrm{yr}$.

[1979]. The scatter in the astronomical azimuths measurements allows for a $25 \%$ deformation rate change from the period before to the period after the 1906 earthquake. This constraint is also met by our model predictions.

Table 2 (top) lists dates of historic Parkfield earthquakes following the Bakun and McEvilly [1984] catalog, time intervals between the events, and corresponding modelcalculated slip deficits at MM (Parkfield earthquake nucleation site) for lower crust relaxation times of 7.5 and 15 years. Guided by the concept of time-dependent accumulation of the slip deficit, we expect more frequent events early in the cycle, following the 1857 earthquake. This is not observed in the entries of Table 2, however, Toppozada [1985] and Toppozada et al. [1990] question the completeness of the Parkfield earthquake catalog and, in fact, suggest more frequent events in the late 1800 s and early 1900 s. Toppozada et al. [1990] list seven $M \geq 5.5$ Parkfield events, including two aftershocks, in the 60 year interval 1870-1930, but only two $M \geq 5.5$ events in the following 60 year interval 1930 1990. Their results further indicate that the earlier Parkfield earthquakes were stronger than the 1934 and 1966 events.

TABLE 2. Parameters of Past Parkfield Earthquakes

\begin{tabular}{lccc}
\hline & $\begin{array}{c}\text { Time Interval, } \\
\text { years }\end{array}$ & $\begin{array}{c}\text { Slip Deficit } \\
\text { m }\end{array}$ & $\begin{array}{c}\text { Slip Deficit } \\
{ }^{\dagger}, \\
\mathrm{m}\end{array}$ \\
\hline Date &
\end{tabular}

Jan. $9(?), 1857$

Apnl 10, 1881

0.96

0.82

March 3, 1901

0.62

0.60

March 3, 1901

March 10, 1922

0.60

0.61

June 5, 1934

0.33

0.33

June 28,1966

0.80

0.84

June 28, 1966

\begin{tabular}{lccc}
$\mu$ (mean) & 21.9 & 0.66 & 0.64 \\
$\begin{array}{l}\sigma_{\mathrm{n}-1} \text { (sample standard } \\
\text { deviation }\end{array}$ & 7.2 & 0.24 & 0.20 \\
$\mu / \sigma_{\mathrm{n}-1}$ & & & \\
\hline
\end{tabular}

Dates are from Bakun and McEvilly [1984]. Slip deficits between successive earthquakes are calculated in this work and correspond to the slip accumulated at MM in our models which neglect fault locking.

* Using $\tau_{\mathrm{r}}$ (lower-crust) $=7.5$ years $\left(\tau_{\mathrm{r}} / \mathrm{h}=1 \mathrm{yr} / \mathrm{km}\right)$.

$\dagger$ Using $\tau_{\mathrm{r}}$ (lower-crust) $=15$ years $\left(\tau_{\mathrm{r}} / \mathrm{h}=1 \mathrm{yr} / \mathrm{km}\right)$.
This is consistent with decreasing rates of accumulated slip deficits as time from the 1857 event increases.

Although the lists of Table 2 are short and possibly not complete, they may be used to calculate the mean $(\mu)$ and standard deviation $(\sigma)$ of Parkfield earthquake repeat time and the corresponding model-derived slip deficits at MM. The relative low ratios $\mu / \sigma$ of order 3 (Table 2, bottom) for all calculated parameters reflect the fact that the statistics are not very good. Nevertheless, these parameters can be used for illustrative predictions of the next Parkfield event. Figure 11 shows cumulative Gaussian probabilities for the occurrence of the next Parkfield earthquake, based on average earthquake repeat time (solid), and time-dependent slip deficits with lower crust relaxation parameters, $\tau_{\mathrm{r}} / \mathrm{h}$, of $1 \mathrm{yr} / \mathrm{km}$ (dash) and $2 \mathrm{yr} / \mathrm{km}$ (dash-dot). Since calculated slip rates along the SAF for the years following 1966 (large lapse time from 1857) are smaller than the far field velocity (see Figures 7 and 8 ), the predictions based on time-dependent slip deficit are delayed with respect to the estimate based on average earthquake repeat time. Specifically, we find that if Parkfield earthquakes are a response to time-dependent slip deficit near Middle Mountain, the next event is predicted for about $1992 \pm 9$ years for lower crust relaxation parameter of $2 \mathrm{yr} / \mathrm{km}$, and $1995 \pm 11$ years for lower crust relaxation parameter $1 \mathrm{yr} / \mathrm{km}$, rather then the $1988 \pm 7$ years estimate based on periodicity in time.

Our results indicate that a viscous stress guide in the lower crust has significant consequences. In the presence of time-

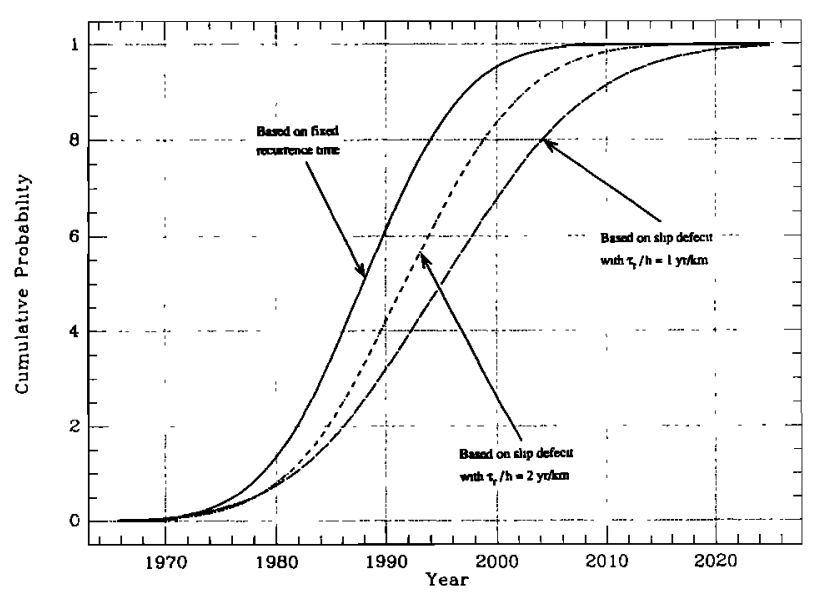

Fig. 11. Cumulative Gaussian probability for the next Parkfield earthquake using statistics of past events. Solid line shows calculation based on average earthquake repeat time. Dashed and dashed-dotted lines show calculations based on slip deficit with lower crust relaxation times of 7.5 years $\left(\tau_{\mathrm{r}} / \mathrm{h}=1 \mathrm{yr} / \mathrm{km}\right)$ and 15 years $\left(\tau_{\mathrm{r}} / \mathrm{h}=2 \mathrm{yr} / \mathrm{km}\right)$, respectively. 
varying tectonic loading rates, earthquakes are expected to occur in a non periodic fashion. Indeed, irregularity in the occurrence of earthquakes characterizes the longest reliable record of historic earthquakes, obtained by the fault trenching analysis of Sieh $\mathrm{et} \mathrm{al}$. [1989]. High loading rates early in the earthquake cycle, especially near the previously faulted area, may result in clustering of earthquakes in time and space. This is compatible with the universal time-space earthquake clustering indicated by the global earthquake catalog analysis of Kagan and Jackson [1991a,b]. High loading rates after the occurrence of an earthquake may also help to account for elevated slip rates in normally creeping fault segments, as was found along the SAF following the 1989 Loma Prieta earthquake [Gladwin et al., 1991; Lisowski et al., 1991b; Gwyther et al., 1992; R. W. Simpson, written communication]. Low loading rates in mature deformation cycles may result in a general decrease of associated deformational events before the occurrence of the next great event. Diffusion-like progress of anelastic deformation along and away from faults may trigger additional deformation phenomena at considerable distances [e.g. Rice and $G u, 1983$; Roeloffs, 1988]. The spread of an anelastic deformation zone away from a ruptured area may offer a mechanism for earthquake sequences showing a 'progression' of events in time and space [Anderson, 1975; Lehner et al., 1981]. Examples include the 1899-1918-1923 SE to NW and 18991937-1954-1968 NW to SE progression on the San Jacinto fault (e.g., Figure 2b of Sanders, [1990]), the 1939-44 North Anatolian sequence [Richter, 1958], the 1979 Coyote Lake - 1984 Morgan Hill - 1988 Alum Rock progression along the Calaveras fault $[D u$ and Aydin, 1990], the 1982 New Idria - 1983 Coalinga - 1985 Kettleman Hill sequence on a blind thrust fault [Stein and Ekström, 1992], the 'paired' San Francisco bay area earthquakes [Ellsworth, 1990] where events on one side of the bay (1836 earthquake on the Hayward fault, 1865 earthquake on the SAF) were followed 3 years later by events on the other bay side (1838 earthquake on the SAF, 1868 earthquake on the Hayward fault), and the recent 1992 Joshua Tree - Landers - Big Bear earthquakes in southern California.

\section{APPENDIX}

Following an initial model-conditioning analysis in which the system is brought to a cyclic steady state, we simulate the 1857 and 1906 events by linearly superposing two ABAQUS runs, each 150 years long. The first run is a re-start (continuation) of the model-conditioning analysis while the second run is a fresh start having zero initial stress and displacement fields. The combined analysis of the two runs meets all initial and boundary conditions of our model.

In the first run we apply to the far field (NE) block face a continuing motion of $17.5 \mathrm{~mm} / \mathrm{yr}$; we use antisymmetric boundary conditions $\left(u_{y}=0, u_{z}=0, \sigma_{x x}=0\right)$ at the NW and $S E$ model faces; and we apply to the earthquake patch the displacement history of Figure Ala: a right-lateral step of magnitude $u_{x}=D / 2$ at 1857 and another right-lateral $D / 2$ step at 1906 , where $\mathrm{D}$ is half the slip of a great earthquake given as $\mathrm{D}=\left(\mathrm{V}_{\mathrm{pl}} / 2\right) \cdot \mathrm{T}_{\mathrm{cy}}=17.5 \mathrm{~mm} / \mathrm{yr} \cdot 150$ years $=2.625 \mathrm{~m}$, with $\mathrm{V}_{\mathrm{pl}}$ being the far field plate velocity and $T_{c y}$ being the earthquake repeat time. The antisymmetric boundary conditions on the SE and NW model faces imply that the slip history of Figure A1a is imposed on both the southeastern (1857) and northwestern (1906) rupture zones.

The second run starts from null initial conditions. As before we use antisymmetric boundary conditions on the SE
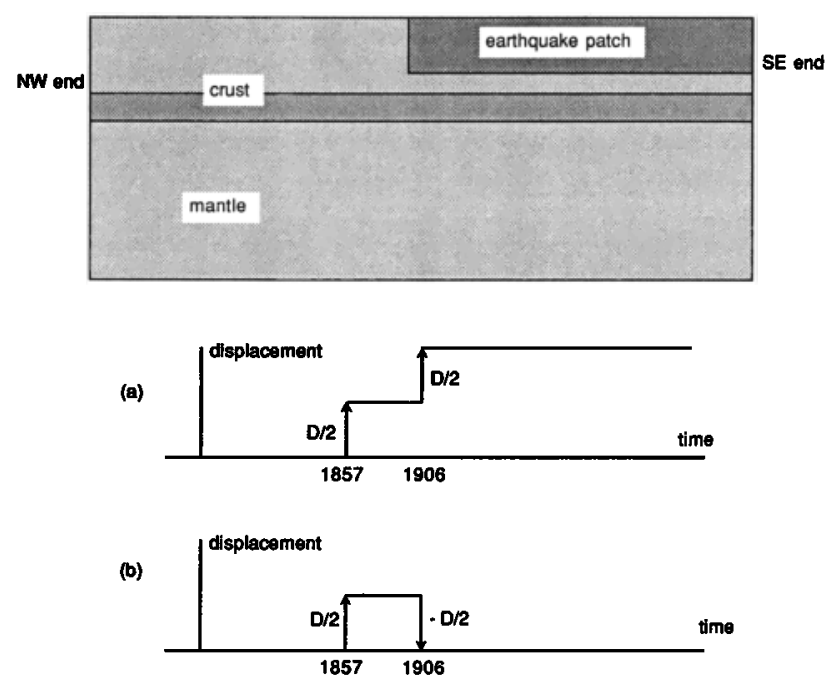

Fig. Ala. Slip history on the earthquake patch, used in conjunction with antisymmetric boundary conditions on the SE and NW model faces. (b). Slip history on the earthquake patch, used in conjunction with symmetric and antisymmetric boundary conditions on the NW and SE model faces, respectively.

model face, but now we apply symmetric boundary conditions $\left(u_{x}=0, \sigma_{x y}=0, \sigma_{x z}=0\right)$ on the NW model face. The imposed displacement history on the earthquake patch during the second run is given by Figure Alb: a right-lateral step of $D / 2$ at 1857 followed by a left-lateral $D / 2$ step at 1906 . The antisymmetric and symmetric boundary conditions on the SE and NW model faces, respectively, generate on the southeastern and northwestern rupture zones displacement histories that are given, respectively, by the positive and negative of Figure Alb.

Adding the results of the first and second runs cancels the improper 1906 displacement on the southeastern zone, cancels the improper 1857 displacement on the northwestern zone, and brings both zones up to the proper displacement $\mathrm{D}$. The combined output gives model deformation due to a constant $35 \mathrm{~mm} / \mathrm{yr}$ far field motion and simulated 1857 and 1906 earthquakes having each a 2.D right-lateral slip and a 150 year earthquake repeat time.

Acknowledgments. We thank Mark Linker for discussions and help during the finite-element analysis, and Wayne Thatcher for various communications and discussions beginning with the earliest parts of this work in 1985. The early work of RD and JRR based on the Elsasser model was aided at various times by Victor $\mathrm{Li}$, Simon Tse and Dan Josell and was supported by USGS under grant 14-08-0001-G1167. The more recent finite element work was supported principally by NSF grant EAR90-04556, with some additional support from the Southern California Earthquake Center. Most of the 3D finite element calculations were performed on Cray 2 and Cray YMP at the National Center for Supercomputer Applications (Illinois) under a grant from NSF. The ABAQUS program was made available at Harvard and NCSA under an academic license from Hibbitt, Karlsson and Sorensen, Inc., Providence, Rhode Island. The manuscript benefitted from comments by Ruth Harris.

\section{REFERENCES}

Anderson, D. L., Accelerated plate tectonics, Science, 187, 1077-1079, 1975.

Bakun, W. H., and T. V. McEvilly, Recurrence models and Parkfield, California, earthquakes, J. Geophys. Res., 89, 3051-3058, 1984.

Burford, R. O., and P. W. Harsh, Slip on the San Andreas fault in central 
California from alignment array surveys, Bull. Seismol. Soc. Am., 70, 1233-1261, 1980.

Carlson, R., H. Kanamori, and K. McNally, A survey of microearthquake activity along the San Andreas fault from Carrizo Plain to Lake Hughes, Bull. Seismol. Soc. Am., 69, 177-186, 1979.

Dmowska, R., V. C. Li and J. R. Rice, Nonuniform stressing in the Parkfield region from interactions between adjacent creeping and locked fault zones, Eos Trans. AGU, 66(46), 985, 1985.

Du, Y., and A. Aydin, Stress transfer during three consequential moderate earthquakes along the central Calaveras fault, Eos Trans. AGU, 71, $1652,1990$.

Ellsworth W. L., Earthquake history, 1769-1989, in The San Andreas Fault System, California, edited by R. Wallace, U.S. Geol. Surv. Prof. Pap. 1515, 1990.

Fares, N., and J. R. Rice, Crustal deformation modeling for San Andreas fault earthquake cycles, Eos Trans. AGU, 1988 Fall Meeting Program, 149, 1988.

Gladwin, M. T., K. S. Breckenridge, R. H. G. Hart, and R. L. Gwyther, Recent acceleration of characteristic creep-strain events at San Juan Bautista, Eos Trans. AGU, 72, 484, 1991.

Gwyther R. L., M. T. Gladwin, and R. H. Hart, A shear strain anomaly following the Loma Prieta earthquake, Nature, 356, 142-144, 1992.

Harris, R. A., and P. Segall, Detection of a locked zone at depth on the Parkfield segment of the San Andreas fault, J. Geophys. Res., 92, 7945$7962,1987$.

Hibbitt, Karlsson and Sorensen, Inc., ABAQUS, Version 4.8, Providence, Rhode Island, 1989.

Kagan Y. Y., and D. D. Jackson, Long-term earthquake clustering, Geophys. J. Int , 104, 117-133, 1991a.

Kagan Y. Y., and D. D. Jackson, Seismic gap hypothesis: ten years after, J. Geophys. Res., 96, 21419-2I431, 1991 b.

King, N. E., and J. C. Savage, Regional deformation near Palmdale, California, 1973-1983, J. Geophys. Res., 89, 2471-2477, 1984.

Lachenbruch, A. H., and J. H. Sass, Thermo-mechanical aspects of the San Andreas, Proceedings, Conference on the Tectonic Problems of the San Andreas Fault System, edited by R. L. Kovach and A. Nur, Stanford Unv Publ. Geol. Sci., 13, 192-205, 1973.

Lehner, F. K., V. C. Li, and J. R. Rice, Stress diffusion along rupturing plate boundaries, J. Geophys. Res., 86, 6155-6169, 1981.

Li, V. C., and J. R. Rice, Crustal deformation in great California earthquake cycles, J. Geophys. Res., 92, 11,533-11,551, 1987.

Linker, M. Fv, and J. R. Rice, The effective viscosity of the San Andreas fault beneath the seismogenic zone: constraints from the response to the 1989 Loma Prieta earthquake, Eos Trans. AGU, 72, 310, 1991.

Lisowski, M. and W. H. Prescott, Short-range distance measurements along the San Andreas fault system in central California, 1975-1979, Bull. Seismol. Soc. Am , 71, 1607-1624, 1981.

Lisowski, M., J. C. Savage, and W. H. Prescott, The velocity field along the San Andreas fault in central and southem California, J. Geophys. Res., 96, 8369-8389, 1991a.

Lisowskı, M., J. C. Savage, and W. H. Prescott, Surface deformation after the Loma Prieta, California, earthquake, Eos Trans. AGU, 72, 119 , $1991 b$.

Lyzenga, G. A., A. Raefsky, and S. G. Mulligan, Models of recurrent strike-slip earthquake cycles and the state of crustal stress, J. Geophys. Res., 96, 21,623-21,640, 1991.

McGarr, A., M. D. Zoback, and T. C. Hanks, Implications of an elastic analysis of in-situ stress measurements near the San Andreas fault, $J$. Geophys. Res., 87, 7797-7806, 1982.

Oppenheimer, D. H., and J. P. Eaton, Moho orientation beneath central California from earthquake travel time. J. Geophys. Res., 89, 10,267$10,282,1984$.

Prescott, W. H., J. C. Savage, and W. T. Kinoshita, Strain accumulation rates in the western United States between 1970 and 1978, J. Geophys. Res , 84, 5423-5435, 1979.

Rice, J. R., The mechanics of earthquake rupture, in Physics of the Earth's
Interior, edited by A. M. Dziewonski and E. Boschi, pp. 555-649, North-Holland, Amsterdam, 1980.

Rice, J. R., and R. Dmowska, Rupture mechanics of slip deficient fault zones, in National Earthquake Hazards Reduction Program Summaries of Technical Reports, vol. XXIII, U.S. Geol. Sur., Open File Rep., 8763, 424-432, 1986.

Rice, J. R., and R. Dmowska, Rupture mechanics of slip deficient fault zones, in National Earthquake Hazards Reduction Program Summaries of Technical Reports, Vol. XXIV, U.S. Geol. Sur., Open File Rep., 87374, 477-482, 1987.

Rice, J. R., and J.- C. Gu, Earthquake aftereffects and triggered seismic phenomena, Pure Appl. Geophys., 121, 187-219, 1983.

Richter, C. F., Elementary Seismology, W. H. Freeman, New York, 1958.

Roeloffs, E. A., Hydrologic precursors to earthquakes: A review, Pure Appl. Geophys., 126, 177-209, 1988.

Sanders C. O., Earthquake depths and the relation of strain accumulation and stress near strike-slip faults in southern California, J. Geophys. Res., 95, 4751-4762, 1990.

Savage, J. C., Comment on "Strain accumulation and release mechanism of the 1906 San Francisco earthquake" by Wayne Thatcher, J. Geophys. Res., 83, 5487-5489, 1978.

Savage, J. C., Strain accumulation in western United States, Annu. Rev. Earth Planet. Sci., 11, 11-43, 1983.

Schultz, S. S., G. M. Mavko, R. O. Burford, and W. D. Stuart, Long-term fault creep observations in central California, J. Geophys. Res., 87 , 6977-6982, 1982.

Segall, P., Fault mechanics, U.S. Nat. Rep. Int. Union Geod. Geophys. 1987-1990, Rev. Geophys., 29 suppl., 864-876, 1991.

Segall, P., and R. Harris, Slip deficit on the Parkfield, California section of the San Andreas fault as revealed by inversion of geodetic data, Science, 233, 1404-1413, 1986.

Segall, P., and R. Harris, Earthquake deformation cycle on the San Andreas fault near Parkfield, California, J. Geophys. Res , 92, 10,51110,525, 1987.

Sibson, R. H., Fault zone models, heat flow, and the depth distribution of earthquakes in the continental crust of the United States, Bull. Seismol. Soc. Am., 72, 151-163, 1982.

Sieh, K., M. Stuiver, and D. Brillinger, A more precise chronology of earthquakes produced by the San Andreas fault in southem Califormia, $J$. Geophys. Res., 94, 603-623, 1989.

Stein, R. S., and G. Ekström, Seismicity and geometry of a 110-km-long blind thrust fault, 2, Synthesis of the 1982-1985 Coalinga earthquake sequence, J. Geophys. Res, 97, 4865-4883, 1992.

Stuart, W. D., R. J. Archuleta, and A. G. Lindh, Forecast model for moderate earthquakes near Parkfield, California, J. Geophys. Res., 90, 592-604, 1985.

Thatcher, W., Systematic inversion of geodetic data in central California, $J$. Geophys. Res., 84, 2283-2295, 1979.

Thatcher, W., Nonlinear strain buildup and the earthquake cycle on the San Andreas fault, J. Geophys. Res., 88, 5893-5902, 1983.

Toppozada, T. R., Questioning the regular sequence of characteristic Parkfield earthquakes, Eos Trans. AGU, 66, 982, 1985.

Toppozada T. R., C. Hallstrom, and D. Ransom, $M \geq 5.5$ earthquakes within $100 \mathrm{~km}$ of Parkfield, CA., Seismol. Res. Lett., 61, 42, 1990.

Tse, S. T., and J. R. Rice, Crustal earthquake instability in relation to the depth variation of frictional slip properties, J. Geophys. Res, 91, 94529472, 1986.

Tse, S. T., R. Dmowska, and J. R. Rice, Stressing of locked patches along a creeping fault, Bull. Seismol. Soc. Am., 75, 709-736, 1985.

Y. Ben-Zion, R. Dmowska, and J. R. Rice, Department of Earth and Planetary Sciences, Harvard University, 20 Oxford Street,

Cambridge, MA 02138

(Received April 29, 1992;

revised September 1, 1992;

accepted September 8, 1992.) 